\title{
ATTENUATION OF IRON OVERLOAD AND EFFECT OF ANTIOXIDANTS SUPPLEMENTATION ON OXIDATIVE STRESS IN HOMOZYGOUS BETA-THALASSEMIA
}

\author{
Ghone RA ${ }^{1}$, Bhagat $\mathrm{SS}^{2}$, Karnik $\mathrm{AC}^{3}$
}

${ }^{1}$ Associate Professor, ${ }^{3}$ Professor \& HOD, Department of Biochemistry, ACPM Medical College, Dhule, ${ }^{2}$ Assistant Professor, Department of Biochemistry, DVVPF's Medical College, Ahmednagar, Maharashtra, India.

\begin{abstract}
It has been projected that ferritin and iron yoke in homozygous thalassemic children is coupled with the enhanced free radical formation and blemished in antioxidative defense coordination. Aim: The purpose of the current study was to analyze the consequence of serum iron, erythrocyte catalase, and erythrocyte superoxide dismutase (ESOD) in patients with beta-thalassemia major. Method: 60 beta-thalassemia major patients were studied before and after supplementation of $\mathrm{A}-\mathrm{Z}$ antioxidants for 20 weeks, and status were compared with 60 age and sex-matched healthy normal. Serum Iron estimation was carried out by Ramsay's Dipyridyl Method. Estimation of erythrocyte superoxide dismutase was done by Kajari Das Method. The levels of Catalase concentration in erythrocytes were analyzed by the Goth method. All the objectives mentioned above were run by using a UV visible Spectrophotometer (Systronix). Results: A marked enhancement was seen in the intensity of serum iron, and superoxide dismutase $(p<0.001)$ with parallel decline was observed in the level of erythrocyte catalase $(p<0.001)$ in homozygous thalassemia patients when compared with healthy subjects. After 20 weeks of regular supplementation of antioxidants A-Z syrup, which consists of multimineral multivitamins, the concentration of catalase was increased whereas iron and ESOD $(\mathrm{p}<0.001)$ were reduced significantly when compared with normal and baselines thalassemic patients. Conclusion: Due to multiple blood transfusions, beta-thalassemia major children are at advanced risk due to secondary iron surplus and intense oxidative stress. Such kind of circumstances may be handled with supplementation of antioxidants A-Z syrup with their regular treatment.
\end{abstract}

Keywords: Beta-thalassemia major; ESOD; Iron burden.

\section{INTRODUCTION}

In 1925, Thomas Cooley and Pearl Lee described a form of severe anemia occurring in children of Italian origin, the Mediterranean region, Africa, Burma, Southeast Asia, including Southern China and Indonesia [1,2].

Worldwide there are about 15 million public have clinically noticeable with thalassemia major disorders. Out of this, about 240 million are carriers of $\beta$ thalassemia with both types. There are around 30 million thalassemic children present in India [3].

$\beta$-Thalassemia major is associated with profound anemia characterized by extreme pallor, jaundice, or failure to thrive, accompanied by poor feeding, irritability, decreased activity, or increased drowsiness. These all characteristics lead towards saturation of surfeit iron in the various organs is mainly seen in homozygous thalassemia patients [4]. Diminished hemoglobin formation and RBC's survival rate, which further ensuing in the glut of unaffected globin chains formation. These excess alpha globin chains form unstable homo-tetramers that further impulsive as inclusion bodies. It leads to severe RBC breakdown and lysis of RBCs. It leads to gross ineffective erythropoiesis (IE). The thalassemic symptoms usually appear within 2-4 months of the child's age [1].

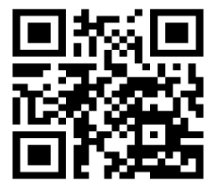

DOI: $10.31878 / \mathrm{ijcbr} .2020 .62 .06$

eISSN: $2395-0471$

pISSN: 2521-0394
The repeated blood transfusion and saturated unstable free $\alpha$-globin's together enhance more and more gastrointestinal iron absorption. This further leads to the iron burden in the body [5]. It is assumed that excess of unpaired globin chains coalesces to form Heinz bodies, which tend to precipitate in the cell and erythrocyte membrane [4]. The iron is a one-way mineral that only enters in the body. In addition to this, frequent blood transfusion leads to progressive iron accretion as there are no excretory pathways. The free iron species are principally accountable for the production of reactive oxygen species (ROS) [2].

Earlier studies have shown that thalassemic patients are exposed to higher oxidative stress and possible consequential accelerated apoptosis. This contributes shorten life span as a result of excess production of reactive oxygen species such as superoxide anion $\left(\mathrm{O}_{2}\right)$, hydroxyl radical $\left(\mathrm{OH}^{*}\right)$, singlet oxygen, and hydrogen peroxide $\left(\mathrm{H}_{2} \mathrm{O}_{2}\right)$ in the erythrocytes $[4,6,7]$.

Because of repeated blood transfusion and increased gastrointestinal iron absorption in the body leads to a violent circle of free radicals. This results in the generation of constant oxidative stress [5,8-10]. Provoked peroxidative tissue injury due to free radicals that escort the severe anemia. The enhanced oxidative stress and disturbed antioxidant defense system stimulate particular unavoidable complications. This accelerates the multi-organ deformity, especially organs that accumulate excess iron, including spleen, liver, heart, pancreas [9].

Antioxidants are critical protective compounds that

Correspondence: : Dr. Sonali S. Bhagat, Assistant Professor, Department of Biochemistry, DVVPF's Medical College, Ahmednagar,Maharashtra, India. Email: bhtsonal@gmail.com 
inactivate free radicals and ROS. They play an essential role in the defense of the cell from oxidative tissue injury. Superoxide radicals generated in excess following antioxidant of the isolated hemoglobin chain is an essential contributor to the hemolytic process; hence it is crucial to measure the erythrocyte superoxide dismutase (ESOD) activity in $\beta$-thalassemia major [5]. Catalase acts on $\mathrm{H}_{2} \mathrm{O}_{2}$ and hydroperoxide and serves as endogenous antioxidants [11].

The concentration of enzymatic antioxidant erythrocytic catalase was found to be considerably reduced when compared with healthy controls and baseline values. The concentration of erythrocyte superoxide dismutase enhanced in $\beta$-thalassemic patients as and when compared with healthy subjects. The depleted activity of erythrocyte catalase in contrast with an enhanced superoxide dismutase and iron expose the existence of harsh oxidative stress in the RBCs of the $\beta$-thalassemia major patients which are on regular blood transfusiondependent $[10,11]$. In homozygous thalassemia patients due presence of continued oxidative stress there is the poor thalassemic erythrocytes develops. This is mainly due to changes in RBC membrane protein pattern when compared to normal erythrocyte, further confirm that there was an enhanced free radical generation. This leads to an altered redox state, which is characterized by gross depletion of antioxidant enzymes and major nutrients [11-13].

In homozygous thalassemia, there was severe antioxidants exhaustion resulting in inadequate protection due to secondary iron overload. Hence, the systematic massive scale of clinical trials in addition to regular treatment, which mainly involves the supplementation of combined antioxidant nutrients, may generate useful for the patients. Further, the antioxidant supplementation therapy in the form of A-Z syrup may be used as an adjunct therapy in homozygous betathalassemia [13].

Keeping this view in mind, the present study was aimed to assess the serum iron levels, which leads to the generation of oxidative stress. To counteract these free radicals, we also evaluate the enzymatic antioxidant concentrations in homozygous thalassemia patients.

\section{MATERIAL AND METHODOLOGY}

Study design: Randomized, single-blinded trial.

Ethical approval: The Institutional Ethical Committee clearance was taken from the institute, and informed consent was obtained.

Study place: Department of Biochemistry, ACPM, Medical College, Dhule, (M.S.)

Study duration: 12 months.

Sample size: Total 120 subjects

Inclusion criteria: This included 60 age and sexmatched healthy normal and $60 \beta$ - thalassemia major children. All patients were already diagnosed by HighPerformance Liquid Chromatography (HPLC) and electrophoretic patterns. All thalassemic patients receive an oral dose of deferiprone as an iron chelator in regular dose $(75 \mathrm{mg} / \mathrm{kg}$ body weight/day or $100 \mathrm{mg} / \mathrm{kg}$ body weight/day as per the serum ferritin concentration). The blood transfusion-dependent aged between 3-12 years.

The common hemoglobin concentration ranged between 3 $-7 \mathrm{gm} / \mathrm{dl}$. During the study period, patients were under the strict supervision of medical professionals.

Exclusion criteria: Patients having a history of CVS diseases, thyroid dysfunction, diabetes mellitus, which induce oxidative stress, were excluded from the study.

Grouping: Group I: Normal healthy volunteers $(n=60)$ Group II: Homozygous beta-thalassemia patients before and after the supplementation of antioxidants syrup A-Z for 20 weeks

\section{Methodology}

From each subject, $4 \mathrm{ml}$ blood was collected aseptically from the antecubital vein. All samples were centrifuged at 3000-3500 rpm for $15 \mathrm{~min}$ to separate serum and erythrocytes, respectively. Polythene tube with cork was used for the collection of separated serum and stored at $20^{\circ} \mathrm{C}$ till its use.

Serum Iron estimation was carried out by Ramsay's Dipyridyl Method [14]. Estimation of erythrocyte superoxide dismutase was done by Kajari Das Method [15]. Catalase activity in RBCs was determined as per the L. Goth method [16]. UV visible Spectrophotometer (Systronix) was used for further analysis of all parameters.

The supplementation was given to the patient's group only in the form of an antioxidant tablet A-Z b.i.d., which was composed of predominantly antioxidant vitamins and trace elements. Antioxidant supplementation was not provided to the control group. The measurement of all parameters from patient groups was accomplished before and after the $20^{\text {th }}$ weeks of the antioxidant supplementation.

Statistical analysis: The statistical analysis was carried out by using the SPSS (Statistical Package for Social Sciences) software, version 16.0 for Windows. The Student ' $Z$ ' test was applied to assess the difference between means of intervention and normal and pre and post-intervention data. All group results were expressed in mean $\pm \mathrm{SD}$.

\section{RESULTS}

Table 1: Antioxidant status in blood samples of control and homozygous $\beta$-thalassemia children patients before and after 20 weeks supplementation of $A-Z$ antioxidants

\begin{tabular}{|c|c|c|c|}
\hline \multirow[t]{2}{*}{ Parameters } & \multirow[t]{2}{*}{ Group 1} & \multicolumn{2}{|c|}{$\begin{array}{l}\text { Group II: Homozygous } \\
\text { Beta-thalassemia children } \\
\text { supplementation of antioxi- } \\
\text { dant A-Z syrup }\end{array}$} \\
\hline & & Before & After \\
\hline $\begin{array}{l}\text { Serum Iron } \\
(\mu \mathrm{g} \%)\end{array}$ & $121.7 \pm 11.9$ & $205.8 \pm 26.5^{* *}$ & $192.2 \pm 19.3^{\$ \$}$ \\
\hline $\begin{array}{l}\text { Erythrocyte } \\
\text { SOD } \\
\text { (U/gm of } \mathrm{Hb})\end{array}$ & $1630.4 \pm 71.3$ & $2192.2 \pm 251^{* *}$ & $1853.4 \pm 243^{\$ \$}$ \\
\hline $\begin{array}{l}\text { Erythrocyte } \\
\text { Catalase (KU/ } \\
\text { L) }\end{array}$ & $202 \pm 49.18$ & $121.9 \pm 39.6^{* *}$ & $161.9 \pm 21.7^{\$ \$}$ \\
\hline
\end{tabular}


${ }^{* *}, \$ \$ \mathrm{P}<0.001$ considered as highly significant. ${ }^{* *}$ Normal vs Group II before suppl of antioxidant, ${ }^{\$ \$}$ Group 2 Before Vs after. Student ' $Z$ ' test was used for individual comparison.

Table 1 illustrates drastically enhanced $(p<0.001)$ levels of serum Iron and ESOD, and the mean value of erythrocyte catalase was lower $(\mathrm{p}<0.001)$ when judged with healthy normal. After 20 weeks of antioxidant supplementation to patients group, it was observed that a significant decrease in the levels of iron and erythrocyte superoxide dismutase as compared with baseline results. Similarly, erythrocyte catalase level was determined to be higher $(\mathrm{p}<0.001)$ at the end of $20^{\text {th }}$ week of the antioxidant supplementation when compared with before supplementation results but not up to the control level.

\section{DISCUSSION}

The aptitude to approximate the allocation of excess iron to forecast its consequences and, therefore, to tailor treatment is amazingly imprecise [10]. Iron overload can be developed by two main mechanisms in betathalassemia major, augmented iron absorption due to ineffective erythropoiesis and repeated and regular blood transfusion [17].

The practical management of iron overload requires reliable estimation of body iron content and distribution as well as an understanding of how iron overload translates into clinical consequences. The goal of transfusion involves the correction of anemia, suppression of erythropoiesis, and inhibition of increased gastrointestinal iron absorption [10]. As there are no excretory mechanism exits, excess iron gets deposited as hemosiderin and ferritin in the liver, spleen, endocardium ${ }^{1}$. The accretion of noxious quantities of iron cause tissue damage which leads to the formation of reactive oxygen species such as hydroxyl radicals $\left(\mathrm{OH}^{*}\right)$, superoxide anions $\left(\mathrm{O}_{2}^{-}\right)$, singlet oxygen and hydrogen peroxide $\left(\mathrm{H}_{2} \mathrm{O}_{2}\right)$ which grossly provoke the oxidative stress and tissue damage in thalassemia major patients via Fenton reaction

$$
\mathrm{Fe}^{2+}+\mathrm{H}_{2} \mathrm{O}_{2} \longrightarrow \mathrm{Fe}^{3+}+\mathrm{OH}^{\bullet}+\mathrm{OH}^{\bullet}
$$

If the assembly of ROS surpassed the capacity of the production of the antioxidant system to eliminate these species, then it will lead to oxidative stress. This oxidative stress and potential consequential hastened apoptosis may contribute to shortening the RBCs life span, amenorrhoea, hypogonadism, other endocrine disorders, and osteoporosis [18].

Our findings are following Eliezer A. Rachmilewitz et al., Kuldeep K. Gupta et al., and Elam Ahed that there were significantly improved serum iron and ESOD levels in patients with homozygous beta-thalassemia as correlated with healthy normal $[1,5,13]$. After the supplementation of antioxidants A-Z syrup for 20 weeks, there was a reduced activity of iron and ESOD were seen whereas catalase was enhanced significantly but not up to the control levels.

Superoxide dismutase acts as the first line of defense against free radicals and ROS, which catalyzes the dismutation of superoxide anion radical $\left(\mathrm{O}_{2}{ }^{-{ }^{-}}\right)$into $\mathrm{H}_{2} \mathrm{O}_{2}$ by reduction $[5,13]$.

The increased ESOD activity was probably due to an increase in the proportion of younger RBC's, and it was a compensatory mechanism to increase the ESOD in response to increased oxidative stress due to iron overload $[1,4,7,13]$.

Attakorn et al. also observed a daily supplementation of vitamin $\mathrm{E}$ for three months. The level of glutathione peroxidase and ESOD were elevated significantly compared to normal and baseline levels of $\beta$ thalassemia major patients [9].

Our findings are in union with the observations made by the Elham Abed Mahdi and Thasinas Dissayabutra et al. The supplementation of antioxidants vitamin $\mathrm{E}$ daily for 90 days at the rate of $200 \mathrm{IU} /$ day reduces the overactivity of ESOD in $\beta$-thalassemia major patients. Antioxidant plays a crucial role in the endogenous defense line against peroxidation of lipid membrane at an early stage through free radical quenching activity $[13,19]$.

Catalase is a foremost erythrocytic antioxidant enzyme hydrolyzing potent $\mathrm{H}_{2} \mathrm{O}_{2}$ at its low concentration to the water molecule. Our examinations show the drastically depleted activity of erythrocytic catalase in homozygous beta-thalassemia victims as compared to the normal before the antioxidant supplementation. These results support the hypothesis made by various researchers like Nandita Das et al., Gerli GC et al., Dibyendu Chakraborty et al. that increased the formation of hydrogen peroxide by the action of superoxide dismutase which can hinder various peroxidase enzyme activities. This may contribute to the further augmentation of oxidative stress [4,20,21].

Elevated activity of erythrocytic Catalase on the $30^{\text {th }}$ day after the supplementation of antioxidants was observed in the thalassemic patient's group. Increased activity of Catalase suggests the decreased formation of $\mathrm{H}_{2} \mathrm{O}_{2}$ and reduces ROS. Supplementation of antioxidants neutralizes as well as reduces the formation of superoxide radicals and $\mathrm{H}_{2} \mathrm{O}_{2}$.

All these findings suggest that daily supplementation of various antioxidants in the required amount boosts the immune response. It also helps to increase the antioxidant protection and depletion in lipid peroxidation, thereby reduction in oxidative tissue injury.

\section{CONCLUSION}

The core of the present study lies in the fact that there was increased oxidative stress in the form of serum iron, ferritin, ESOD, and reduced catalase activity in patients at baseline levels. Due to repeated and regular blood transfusion for the survival of beta thalassemic children results in enhanced free iron surplus and giving credence to serum ferritin levels, which causes the enhanced generation of oxidative stress. This leads to the development of various abnormalities in the body.

The frequent and regular antioxidant syrup supplementation to the homozygous beta-thalassemia patients may improve the overall antioxidative status. Antioxidants neutralize the free radicals production along with the synthesis of the new RBCs and improve the overall concentration of hemoglobin.

Clinical uses: To date, the treatment accessible for this 
homozygous beta-thalassemia is the chelation of excess of iron, transplantation of bone marrow, and stem cell therapy. However, these treatments are costly, compromised by noncompliance, and hence these patients only depend on frequent blood transfusion throughout their life. One of the ways to may boost the survival rates of such homozygous thalassemic children is the inhibition of the consequence of oxidative stress. Combined antioxidant therapy with compliance on regular treatment had improved the antioxidant status, reduce hemolysis rate, and improve the hepatic status by both decrease liver iron concentration and the degree of liver fibrosis.

Acknowledgments: The author sincerely acknowledges Dr. Mhaske SN. and Dr. Kothari, Dept. of Paediatrics DVVPF's Medical College, Ahmednagar, and Dr. Kamble, MD Paediatrics, Civil Hospital Ahmednagar, for allowing to collect the blood samples from Hospital.

\section{Conflict of interest : Nil}

Source of funding : Nil

\section{REFERENCES}

[1] Eliezer AR, Patricia G. How I treat thalassemia. Blood 2011; 118:3479-88

[2] Nancy F, Olivieri MD. The $\beta$ - thalassemias. The New England J. of Medicine 1999;341(2):99-108

[3] Naveen T. Prevention of Thalassemia in India. Indian Pediatrics 2007;44:647-8

[4] Nandita Das, Chowdhury TD, Chattopadhyay AD. Attenuation of oxidation stress induced changes in thalassemic erythrocytes by Vitamin E. Pol J Pharmocol 2004; 56:85-96

[5] Kuldeep KG, Amit M, Archana T. Production of reactive oxygen species, Its effects, drugs and plant extract used as an antioxidant, chelator on thalassemic patients: A Review. International J of Pharma Sciences and Research 2011;2(9):2278-85

[6] Asmaa Nafady, Sanaa Shaker Ali, Hosney Mohammed Ahmed EI Masry, Khaled Abdel Baseer et al. Oxidative stress in pediatric patients with $\beta$ - thalassemia major. Egyptian Journal of Haematology 2017;42(3):123-7

[7] Elijah K Golgberg, Sushrita Neogi, AshutoshLal, Annie Higa et al. nutritional deficiencies are common in patients with transfusion dependent thalassemia and associated with iron overload. J of Food and Nutrition research 2018; 6(10):674-81

[8] AnujaAdarsh, Asha Khubchandani, Disha Gajjar. Alteration in trace elements (s.iron, s.zinc, copper) in thalassemia major patients after chelation therapy. Int J Med Sci Educ. 2019; 6(1):63-5

[9] Attakorn Palasuwan, Methee Sriprapun, Winai Dahlan, Rataya Luechapudiporn et al. Antioxidant protection in hemoglobin E trait subjects after vitamin E supplementation. Southeast Asian J Trop Med Public Health 2008;39(1):82-9

[10] Attia MMA, Sayed AM, Mohammed FA, El-Alfy MA. Effect of Antioxidant Vitamins on Some
Hemoglobin Properties and Erythrocytes in Homozygous Beta Thalassemia. Romanian J Biophys 2011;1(21):1-16

[11] Ghone RA, Kumbar KM, Suryakar AN, Katkam RV, Joshi NG. Oxidative stress and disturbance in antioxidant balance in beta thalassemia major. Indian Journal of Clinical Biochemistry 2008;23 (4):337-40

[12] Shazia Q, Mohammad ZH, Taibur Rahman, Hossain Uddin Shekhar. Correlation of oxidative stress with serum trace elements levels and antioxidant enzyme status in beta thalassemia major patients: A review of the literature. Anemia 2012;2012:1-7

[13] Elham Abed Mahdi. Relationship between oxidative stress and antioxidant status in beta thalassemia major patients. Acta Chim. Pharm. Indica: $2014 ; 4(3): 137-45$

[14] Varley H. Ramasaysdipyridyl method for iron. In: Practical clinical biochemistry $4^{\text {th }}$ Ed. 1967: 472

[15] Kajari Das. A modified spectrophotometric assay of superoxide dismutase using nitrate formation by superoxide radicals. Indian $\mathrm{J}$ of Biochem and Biophys 2000; 57: 201-4

[16] Goth L. A simple method for determination of serum and erythrocyte catalase activity and the revision of the reference range. Clinica Chimica Acta $1991 ; 196: 143-5$

[17] Fatemeh B, Sedigheh S, Mahtab BE. Total antioxidant status in patients with major $\beta$ thalassemia. Iran J Pediatr 2011;21(2):159-65

[18] Abolfazl M, Parviz A, Ali- Asghar P. Zinc and copper status in children with beta thalassemia major. Iran J Pediatr 2010;20(3):297-302

[19] Thasinas Dissayabutra, Piyaratana T, Panya S. The benefits of vitamin $\mathrm{C}$ and vitamin $\mathrm{E}$ in children with $\beta$ - thalassemia with high oxidative stress. J Med Assoc Thai 2005;88(4):317-21

[20] Gerli GC, Berettz L, Bianchi M, Pellegatta A, Agostoni A. Erythrocyte superoxide dismutase, catalase and glutathione peroxidase activities in beta-thalassemia (major and minor). Scand $J$ of Haematol 1980;25(1):87-92

[21] Dibyendu C, Bhattacharyya M. Antioxidant defense status of red blood cells of patients with $\beta$ thalassemia and E $\beta$ - thalassemia. Clinica Chimica Acta 2001;305(1):123-9 